\title{
Improved Extraction of Intracellular Biogenic Selenium Nanoparticles and their Specificity for Cancer Chemoprevention
}

Praveen Sonkusre, Ravikanth Nanduri, Pawan Gupta and Swaranjit Singh Cameotra*

Institute of Microbial Technology, Sector 39 A, Chandigarh 160036, India

\begin{abstract}
Selenium is reported to have excellent anticancer activity at higher doses. However, due to its low therapeutic index, it is desirable to have a selenium form with lesser toxicity even at high therapeutic dose; alternatively it would be progressive to attempt efficacious preparation at very low concentration. In this study, selenium nanoparticles were synthesized biologically by Bacillus licheniformis $\mathrm{JS} 2$, and a method was developed for extraction and purification of intracellular nanoparticles. Characterization of extracted nanoparticles for shape, size, and purity indicated that the particles were spherical with diameters ranging between 40 and $180 \mathrm{~nm}$, composed of selenium and capped with a few functional groups that provide steric stability to them. These neutral charged, non-agglomerating selenium nanoparticles at a concentration as low as $2 \mu \mathrm{g} \mathrm{Se} / \mathrm{mL}$ were efficacious in inhibiting proliferation and inducing caspase independent necrosis to human prostate adenocarcinoma cells (PC3) without causing any significant toxicity to human peripheral blood mononuclear cells.
\end{abstract}

Keywords: Bacillus licheniformis JS2; Steric stability; Selenium nanoparticles; Necrosis; PC3; Human peripheral blood mononuclear cells

\section{Introduction}

Selenium is an essential trace element that plays several crucial roles in mammalian physiology [1]. As an integral part of glutathione peroxidase and thioredoxin reductase enzyme, it works as a potent antioxidant agent and has been found to be involved in thyroid hormone metabolism and fertility improvement. Evidence suggests that selenium also plays a role in the prevention of several diseases including cardiovascular disease, arthritis, muscular dystrophy, and cystic fibrosis; in addition it is known to have anticancer activity [2]. Due to low therapeutic index of organic and inorganic selenium, the use of selenium in nanoparticle (NP) form is gaining a great deal of attention [3,4]. Chemically synthesized selenium nanoparticles (SeNPs) have been studied as a potential cancer therapeutic agent and drug carrier [5,6] with excellent antioxidant activity $[7,8]$. They appear to have physiological properties similar to those of other selenium compounds, such as sodium selenite, Semethylselenocysteine, and selenomethionine (SeMet) [2,3,7], although other physiological activities need to be studied further. It has been also reported that SeNPs have better bioavailability and less toxicity than other organic and inorganic selenocompounds [5,7,9]. Because of key advantages over chemical and physical synthesis, biological synthesis of NPs is rapidly becoming an important field for study. Biological synthesis is clean, non-toxic, and eco-friendly; additionally it utilizes less energy than chemical and physical synthesis with an efficient use of material without generation of harmful by-products [10]. In addition, there are two other major advantages of biologically synthesized NPs over those chemically synthesized: increased biocompatibility and much greater stability [11]. Many reports have demonstrated the biosynthesis of various metal and metalloid NP by bacteria, fungus, and other microorganisms, under metal or metalloid salt stress, respectively. Bacteria are known to produce metal, metalloid, and metal oxide NPs with various structures compositions, sizes, and densities. Many of these organisms synthesize NPs intracellularly but few extracellularly [11-16]. If fully developed, these biological systems could be utilized commercially for nanomaterial synthesis [17].

Unfortunately, the purity of the particles from this eco-friendly synthesis process can be questionable. Since these particles are synthesized by microorganisms, there is a high possibility that the NPs produced are associated with the microorganism itself, various microbial cellular components, or both $[15,16,18]$. To overcome this problem, it is paramount to investigate improved extraction protocols. Recent efforts are focused on bacteria that synthesize NPs extracellularly or have used bacterial supernatants containing reductase enzymes and probably some other factors responsible for metal reduction and NP synthesis so that particles can be easily extract and are less likely to be associated with microbial components $[15,19,20]$. Many bacterial species have been reported to synthesize NPs very q u i ckly and efficiently but intracellularly. However, because of the current unavailability of an efficient method for intracellular NP recovery and associated agglomeration issues [21], researchers cannot utilize the potential of these highly efficient bacteria and are more focused on extracellular NP-synthesizing microorganisms.

Here, we report a novel method for the extraction and purification of intracellular selenium NPs from the Gram positive bacteria Bacillus licheniformis JS2. We have developed a new procedure that utilizes lysozyme and a French press for complete bacterial cell lysis. This protocol is very efficient and allows the recovery of pure and clean intracellular SeNPs.

Additionally, we studied the effect of these biogenic SeNPs on human prostate adenocarcinoma cell line PC3 and observed excellent necrosis inducing ability at very low selenium concentration without a significant effect on human peripheral blood mononuclear cell (hPBMC) viability.

*Corresponding author: Swaranjit Singh Cameotra, Institute of Microbial Technology, Sector 39 A, Chandigarh 160036, India, Tel: 0172-6665223; Fax : 0172-2690632/585; E-mail: ssc@imtech.res.in

Received March 13, 2014; Accepted April 09, 2014; Published April 15, 2014

Citation: Sonkusre P, Nanduri R, Gupta P, Cameotra SS (2014) Improved Extraction of Intracellular Biogenic Selenium Nanoparticles and their Specificity for Cancer Chemoprevention. J Nanomed Nanotechnol 5: 194. doi:10.4172/21577439.1000194

Copyright: (c) 2014 Sonkusre P, et al. This is an open-access article distributed under the terms of the Creative Commons Attribution License, which permits unrestricted use, distribution, and reproduction in any medium, provided the original author and source are credited. 


\section{Materials and Methods}

\section{Microorganism and culture conditions}

Bacterial strain Bacillus licheniformis JS2, isolated from seleniferous agricultural soil from Jainpur Village located in the Nawahshahr district (latitude $31^{\circ} 07^{\prime} \mathrm{N}$ and longitude $76^{\circ} 08^{\prime} \mathrm{E}$ ) of Punjab, India, was used for SeNP synthesis under aerobic conditions. Bacteria was routinely cultivated and maintained on tryptic soya broth and agar plates at $37^{\circ} \mathrm{C}$ [22].

\section{Reagents}

Tryptic soya broth and agar were purchased from Hi-Media. Lysozyme, lauryl-sulfate (sodium dodecylsulfate, SDS), absolute ethanol, Histopaque-1077, and menadione were obtained from Sigma. Tris-buffer, $\mathrm{HCl}$, 1-octanol, and chloroform were purchased from Merck. A silver staining kit for protein detection was purchased from Pierce Thermo Scientific, and the manufacturer's protocol was followed. Type II Millipore water was used in all experiments. RPMI medium 1640, F12K nutrient mixture medium, fetal bovine serum (FBS), and penicillin-streptomycin solution (Pen-Strep) were procured from Invitrogen for mammalian cell growth, maintenance, and experimental setup. All plastic ware for cell culture was purchased from Nunc. XTT sodium salt for the cell viability assay was purchased from Santa Cruz Biotechnology. L-selenomethionine and an AnnexinV-FITC apoptosis detection kit were purchased from Calbiochem, and the manufacturer's protocol was used. ApoTox-Glo Triplex assay kit was purchased from Promega and the manufacturer's protocol was followed.

\section{Synthesis and extraction of selenium nanoparticles}

Bacillus licheniformis JS2 was used to synthesize SeNPs aerobically
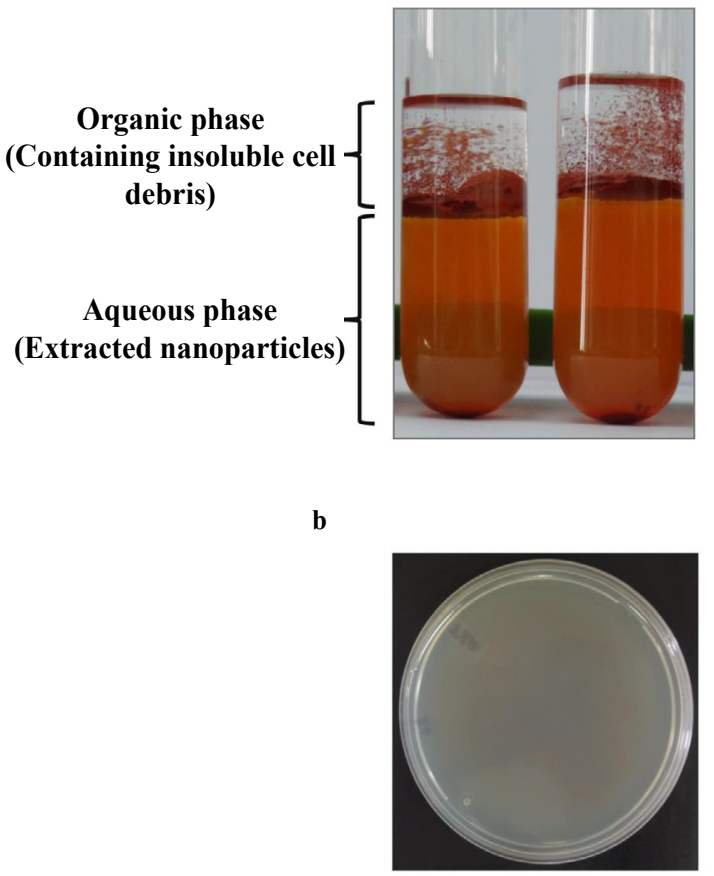

Figure 1: (a) Extraction of purified SeNPs by a two-phase water-octanol extraction system. (b) $150 \mu \mathrm{g}$ purified SeNPs spread on TSA plate showing absence of viable bacterial cell(s) in NP sample. under $1.8 \mathrm{mM}$ sodium selenite stress. A bacterial culture at $0.02 \mathrm{OD}_{600}$ was allowed to grow for $15 \mathrm{~h}$ at $200 \mathrm{RPM}$ at $37^{\circ} \mathrm{C}$ in a 2 liters culture flask containing $600 \mathrm{~mL}$ of TSB medium. Cells were collected by centrifugation at $6000 \times \mathrm{g}$ for $10 \mathrm{~min}$ and then transferred to a 1 liter culture flask containing $300 \mathrm{~mL}$ of TSB medium supplemented with 1.8 $\mathrm{mM}$ sodium selenite. Bacteria were allowed to grow for $5 \mathrm{~h}$ at $200 \mathrm{RPM}$ at $37^{\circ} \mathrm{C}$. Cells were collected by centrifugation at $12500 \times \mathrm{g}$ for $10 \mathrm{~min}$ and transferred to a $50 \mathrm{~mL}$ centrifuge tube. The pellet was washed and resuspended in $20 \mathrm{~mL}$ of sterile water. To this $120 \mu \mathrm{l} \mathrm{of} 100 \mathrm{mg} / \mathrm{mL}$ ( 12 $\mathrm{mg}$ ) lysozyme solution was added, and the tube was kept at $37^{\circ} \mathrm{C}$ for $3 \mathrm{~h}$. The culture was then crushed under high pressure (1500 Psi) in a French press. The resultant slurry containing both cell debris and NPs was washed four times at $15000 \times \mathrm{g}$ for $10 \mathrm{~min}$ with $1.5 \mathrm{M}$ Tris- $\mathrm{HCl}$ ( $\mathrm{pH}$ 8.3) containing 1\% SDS. The resultant pellet containing NPs and the insoluble cell wall fraction was washed and resuspended in $16 \mathrm{~mL}$ of sterile water. Aliquots of $4 \mathrm{~mL}$ were transferred to four high tensilestrength glass tubes (Schott GL18), and $2 \mathrm{~mL}$ of 1-octanol were added. The solution was mixed vigorously on a vortex mixture for few min and centrifuged at $2000 \mathrm{x} \mathrm{g}$ for $5 \mathrm{~min}$ at $4^{\circ} \mathrm{C}$. The tubes were then kept undisturbed at $4^{\circ} \mathrm{C}$ for $24 \mathrm{~h}$. The upper phase and interface containing the insoluble cell fraction were discarded, and the bottom water phase was transferred to a clean $50 \mathrm{~mL}$ centrifuge tube. This was washed sequentially with chloroform, absolute ethanol, $70 \%$ ethanol, and water at $16000 \times$ g. Collected NPs were resuspended in water and stored at $4^{\circ} \mathrm{C}$. NPs could also be resuspended and stored in $50 \mathrm{mM}$ Tris- $\mathrm{HCl}(\mathrm{pH}$ 7.4). $150 \mu \mathrm{g}$ of these extracted and purified SeNPs were spread on tryptic soya agar plates to observe the cell lysis efficiency of the process.

\section{Characterization of selenium nanoparticles}

SeNPs were characterized for shape, size, and purity by using various spectrophotometric [dynamic light scattering (DLS), energy dispersive X-ray spectroscopy (EDX), Fourier transformed infrared spectroscopy (FTIR)], microscopic [scanning electron microscopy (SEM), transmission electron microscopy (TEM)], and electrophoresis (SDS-PAGE) techniques. Samples for TEM were prepared by placing a drop of NP suspension on carbon-coated copper grids. The images were visualized at $200 \mathrm{kV}$ on a JEOL JEM 2100 TEM microscope. SEM samples were prepared by a standard fixation procedure used for bacterial visualization [20]. Images of nanoparticles were obtained on a Zeiss EVO 40 SEM microscope. EDX analysis of air-dried NP samples was performed on a Bruker AXS X-Flash Detector 4010 Energy Dispersive X-Ray Microanalyser to determine the composition and purity of the particles. The size distribution and surface charge on the SeNPs were measured in a suspension on a Zetasizer Nano ZS particle analyzer (Malvern). FTIR (Thermo Scientific NICOLET iS10) studies in the range of $800 \mathrm{~cm}^{-1}$ to $3500 \mathrm{~cm}^{-1}$ were performed to determine the functional groups on the NPs.

\section{Quantification of selenium}

Extracted SeNPs were digested overnight with 3:1 nitric/ perchloric acid. Digested samples were analyzed in an atomic absorption spectrophotometer (AA-6800, Shimadzu) to determine the concentration of selenium present. An air-acetylene (oxidizing) flame and selenium cathode lamp were used and a wavelength of $196 \mathrm{~nm}$ was selected to measure absorption of incident light.

\section{Protein-NP association}

The NP sample was denatured at $95^{\circ} \mathrm{C}$ for $10 \mathrm{~min}$ in gel loading buffer then electrophoresed on $15 \%$ SDS-PAGE at $12 \mathrm{~mA}$. Silver staining was performed to analyze the proteins associated with the NPs. 


\section{Stability of NPs at physiological temperature, $\mathrm{pH}$ and buffer conditions}

NPs were tested for agglomerate formation at physiological temperature and $\mathrm{pH}$. Extracted NPs were kept undisturbed at $37^{\circ} \mathrm{C}$ for 5 $h$ in various concentrations of bicarbonate buffer, $0.1 \mathrm{M}, 0.01 \mathrm{M}$, and 0 . $001 \mathrm{M}, \mathrm{pH}$ 7.4. Accumulation of NPs at the bottom of microcentrifuge tube was used as a sign of agglomerate formation.

\section{Cell lines and cell culture}

A human prostate adenocarcinoma cell line (PC3) was obtained from the National Centre for Cell Science, Pune, India. The cells were grown in F12K media supplemented with penicillin (100 units $/ \mathrm{mL}$ ), streptomycin (50 units $/ \mathrm{mL})$, and fetal bovine serum $(10 \%)$, at $37^{\circ} \mathrm{C}$ in a humidified incubator with $5 \% \mathrm{CO}_{2}$.

Human peripheral blood mononuclear cells (hPBMC) were isolated from healthy volunteers by Ficoll-Hypaque (Histopaque-1077) density gradient centrifugation. Cells were maintained in RPMI 1640 medium supplemented with $10 \mathrm{mM}$ HEPES, penicillin (100 units $/ \mathrm{mL})$, streptomycin (50 units $/ \mathrm{mL}$ ), and fetal calf serum $(10 \%)$, at $37^{\circ} \mathrm{C}$ in a humidified incubator with $5 \% \mathrm{CO}_{2}$.

\section{XTT assay}

Cell viability was determined by quantifying the ability of cells to convert water-soluble XTT sodium salt [2,3-bis(2-methoxy-4-nitro5-sulfophenyl)-2H-tetrazolium-5-carboxanilide] to a water-soluble, orange-colored formazan product. PC3 cells were seeded with F12K medium in 96-well tissue culture plates at a density of $3.5 \times 10^{3}$ cells per well. After $24 \mathrm{~h}$ of resting period at $37^{\circ} \mathrm{C}$, cells were treated with SeNPs or SeMet at various concentrations, 1, 2, 4, and $6 \mu \mathrm{g} \mathrm{Se} / \mathrm{mL}$, and cultured for $24 \mathrm{~h}$ at $37^{\circ} \mathrm{C}$. After the addition of $100 \mu \mathrm{l}$ of freshly prepared XTT solution $(0.5 \mathrm{mg} / \mathrm{mL})$ supplemented with menadione (final concentration $1 \mu \mathrm{M}$ ) to each well, cells were incubated for 3 $\mathrm{h}$ at $37^{\circ} \mathrm{C}$. Plates were then analyzed at $490 \mathrm{~nm}$ on a BioTek Power Wave Microplate reader. Production of an orange color in this assay corresponds to cell viability. Respective morphological responses to selenium treatment were visualized at $40 \mathrm{X}$ under bright field in Olympus IX71 microscope.

\section{Flow cytometry}

PC3 cells were seeded in 12-well plates at a density of $2 \times 10^{5}$ cells per well in F12K medium supplemented with $10 \%$ FBS and kept at rest for $24 \mathrm{~h}$ at $37^{\circ} \mathrm{C}$. After the rest period, hPBMC isolated from the blood of healthy volunteers were seeded in RPMI medium supplemented with 10 mM HEPES and $10 \%$ FCS in 12-well tissue culture plates at a density of $5 \times 10^{5}$ cells per well. Both the cell types were treated with SeNPs or SeMet at a concentration of $2 \mu \mathrm{g} \mathrm{Se} / \mathrm{mL}$, and incubated for $24 \mathrm{~h}$. Cells were harvested, and an AnnexinV-FITC Apoptosis Detection Kit was used to stain cells with annexin $\mathrm{V}$ and propidium iodide according to the manufacturer's instructions. Cells were acquired in a BD AccuriC6 Flow Cytometer (BD Biosciences). The data analysis was performed with FlowJo software.

\section{Caspase- $3 / 7$ activity}

Caspase-3/7 activity was determined by providing a luminogenic caspase- $3 / 7$ substrate, containing the tetra peptide sequence DEVD, to the NP treated cells. PC3 cells were seeded in 96-well opaque walled plate at a density of $8 \times 10^{3}$ cells per well in F12K medium supplemented with $10 \% \mathrm{FBS}$ and kept at rest for $24 \mathrm{~h}$ at $37^{\circ} \mathrm{C}$. Fresh hPBMC isolated from the blood of healthy volunteers were seeded in RPMI medium supplemented with $10 \mathrm{mM}$ HEPES and 10\% FCS at a density of $20 \times 10^{3}$ cells per well. Both the cell types were treated with SeNPs at a concentration of $2 \mu \mathrm{g} \mathrm{Se} / \mathrm{mL}$, and incubated for $12 \mathrm{~h}$ at $37^{\circ} \mathrm{C}$. ApoToxGlo Triplex assay kit was used according to manufacturer's instructions. Glow-type luminescent signal proportional to the amount of caspase activity was measured by GloMax-96 Microplate Luminometer.

\section{Ethics statement (Human PBMC)}

hPBMC were obtained and used strictly according to the ethical guidelines for biomedical research on human subjects by the Central Ethics Committee on Human Research, Indian Council of Medical Research-2000 as well as the standards in the Declaration of Helsinki. Written information about the study and the written consent were in the native language of the subject (English, Hindi, and Punjabi).

\section{Statistical analysis}

The data represented here are the mean \pm SEM from at least three independent experiments. Statistical significances were examined using two-tailed Student's t-test.

\section{Results}

\section{Synthesis, extraction, purification, and characterization of} SeNPs

SeNPs were synthesized by the intracellular conversion of toxic selenite ions $\left(\mathrm{Se}^{+4}\right)$ into nontoxic elemental SeNPs $\left(\mathrm{Se}^{0}\right)$ under aerobic conditions by the bacterium Bacillus licheniformis JS2 [22]. A method reported by Shakibaie and colleagues was applied for recovery of intracellular SeNPs. However, we found that the NPs obtained by this method were associated with the bacteria and formed agglomerates after recovery (Supplementary Figure 1).

We improved the cell lysis procedure and recovered intracellular SeNPs by bacterial cell lysis using lysozyme and French press, cleaned by successive washes with Tris- $\mathrm{HCl}$ buffer and finally separated from insoluble debris by two-phase water-octanol extraction (Figure 1a). Spreading of purified and cleaned SeNPs on TSA plate showed no bacterial (Bacillus) growth indicating the cell lysis process is highly efficient (Figure 1b).

DLS data indicate the size distribution of the SeNPs ranged from 40 to $180 \mathrm{~nm}$ (Figure 2a). No charge was observed on the surface of the SeNPs by a Zeta potential measurement (Figure $2 b$ ). The particles were found to be stable at physiological temperature and $\mathrm{pH}$. When kept at $37^{\circ} \mathrm{C}$ for $5 \mathrm{~h}$ in various concentration of bicarbonate buffer, the particles with no charge on the surface did not form agglomerates, whereas the negatively charged particles $(-29 \mathrm{mV})$ agglomerated and settled to the bottom of the tube (Figure 2c).

Electron microscopy was performed to determine the exact structure and size of the SeNPs. SEM and TEM images (Figure 3a and $3 b$ ) showed that the particles are spherical in shape with an average diameter of 120 $\mathrm{nm}$ and did not forming aggregates. EDX spectra of the SeNPs indicated that the particles are composed of only selenium (Figure 3c).

SDS-PAGE of SeNPs ( $50 \mu \mathrm{g} \mathrm{Se})$ followed by silver staining suggests there are few bacterial proteins associated with the NPs. Protein bands of $70 \mathrm{KDa}$ and $\sim 50 \mathrm{KDa}$ were visible although the quantity of protein was very low (Figure 4a). FTIR analysis showed that the particles have some functional groups attached to their surfaces. Most of the peaks represent protein or peptide groups: the peak at $3405 \mathrm{~cm}^{-1}$ corresponds to the $\mathrm{N}-\mathrm{H}$ stretch; the peaks at 2917 and $2849 \mathrm{~cm}^{-1}$ represent the $\mathrm{C}-\mathrm{H}$ stretch; the 

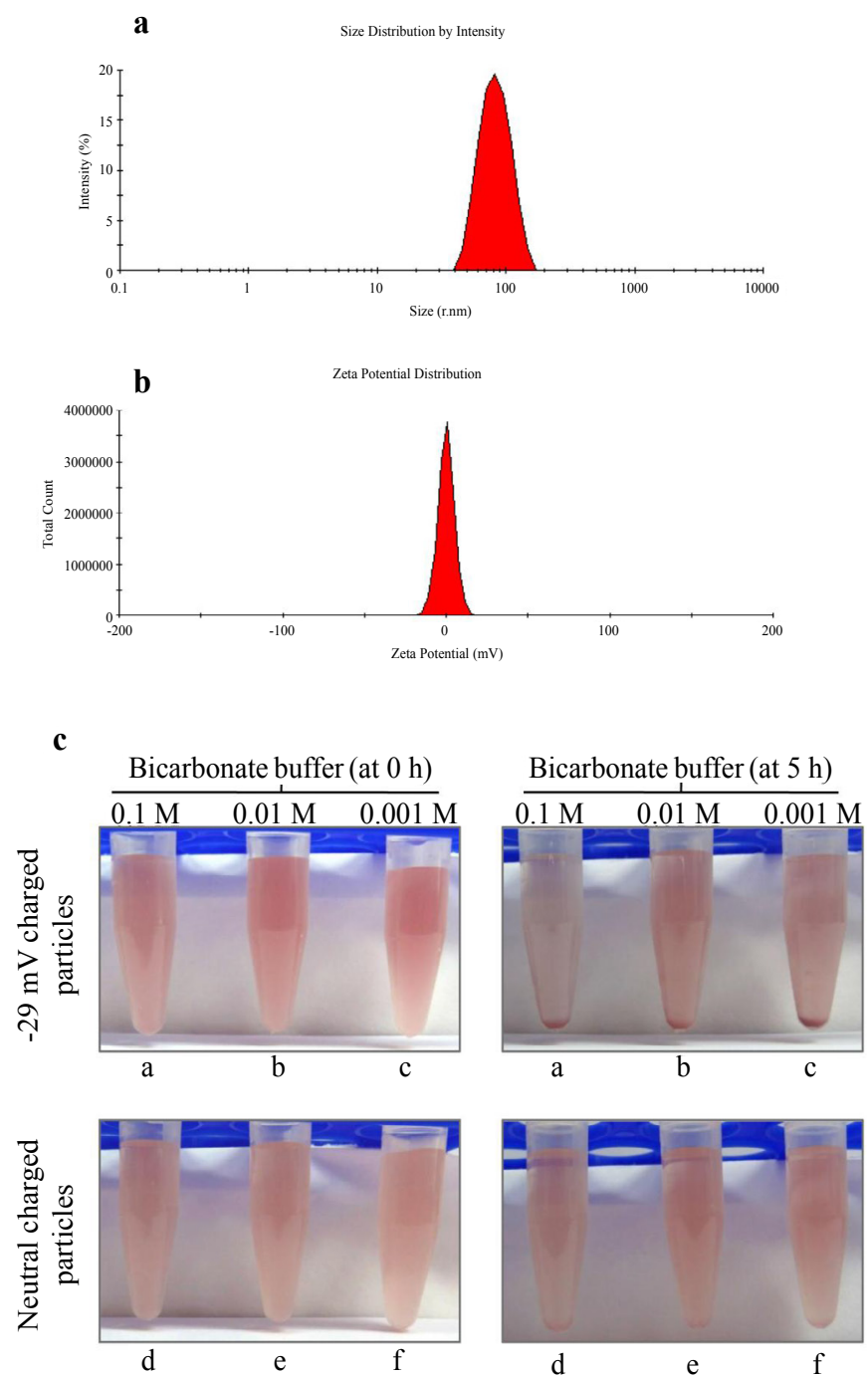

Figure 2: (a) DLS analysis of SeNPs showing the size distribution of particles. Data indicates particles are polydisperse, with sizes ranging from $40 \mathrm{~nm}$ to $180 \mathrm{~nm}$. (b) Zeta potential analysis showing the charge distribution on the SeNPs. The charge on the particles was found to be zero. (c) Comparison of the stability of SeNPs

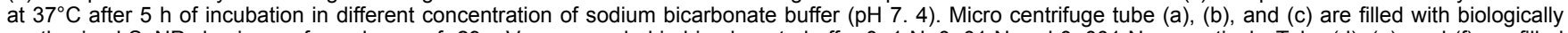
synthesized SeNPs having surface charge of $-29 \mathrm{mV}$ resuspended in bicarbonate buffer $0.1 \mathrm{~N}, 0.01 \mathrm{~N}$ and $0.001 \mathrm{~N}$ respectively. Tube (d), (e), and (f) are filled with biologically synthesized SeNPs having surface charge of $0 \mathrm{mV}$ resuspended in bicarbonate buffer $0.1 \mathrm{~N}, 0.01 \mathrm{~N}$ and $0.001 \mathrm{~N}$ respectively. Particles having the surface charge settled due to agglomeration at $37^{\circ} \mathrm{C}$.

peaks at 1633,1462 , and $1384 \mathrm{~cm}^{-1}$ were assigned to the amide bond; and the peak at $1050 \mathrm{~cm}^{-1}$ was assigned to the $\mathrm{C}-\mathrm{O}$ stretch (Figure $4 \mathrm{~b}$ ).

\section{Effect of biogenic SeNPs on prostate cancer cell viability}

The effect of SeNPs on PC3 cell viability was studied by performing an XTT assay on cells cultured in the presence of various concentrations of the SeNPs. We found that the SeNPs reduced the viability of the prostate cancer cell line PC3 at all the concentrations tested, 1, 2, 4, and $6 \mu \mathrm{g} \mathrm{Se} / \mathrm{mL}$. Only $45 \%$ cell viability was observed at $6 \mu \mathrm{g} \mathrm{Se} / \mathrm{mL}$. Because SeMet is the major dietary supplement form of selenium, it was used as a control and caused no significant decrease in cell viability (Figure 5a). In support to XTT results, bright field micrograph of selenium treated PC3 cells confirms the cellular damage on SeNP treatment. Most of the cells lost their typical morphology, became shrunken. Detachment of cells from the plate surface has been observed after SeNP treatment. Decrease in the adherent cell number was observed with the increase in SeNP concentration, whereas, no change was observed in SeMet treated cells (Figure 5b).

\section{Biogenic SeNPs induce late apoptosis and/or necrosis in PC3 cancer cells}

To determine if the reduction in cell viability of PC3 cells treated with SeNPs was caused by induction of apoptosis or necrosis, we performed AnnexinV-FITC and propidium iodide (PI) staining after treating the PC3 cells for $24 \mathrm{~h}$ with SeNPs or SeMet at a concentration of $2 \mu \mathrm{g} \mathrm{Se} / \mathrm{mL}$. hPBMC were used as a non-cancerous control. Fluorescence-activated cell sorting (FACS) analysis suggested that at a very low concentration, 2 $\mu \mathrm{g} \mathrm{Se} / \mathrm{mL}$, the SeNPs induced late apoptosis and/or necrosis in PC3 cells (Figure 6a). At this concentration of SeNP no significant apoptosis or necrosis was seen in hPBMCs (Figure 6b).

To find the mechanism of cell death ApoTox-Glo triplex assay was performed on NP treated PC3 cells and hPBMC to measure 
a

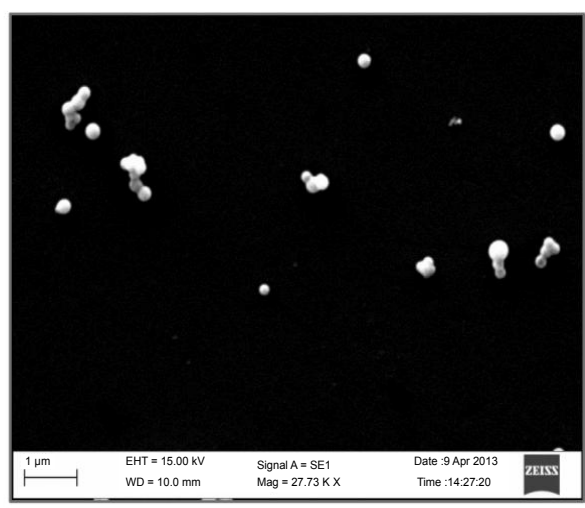

b

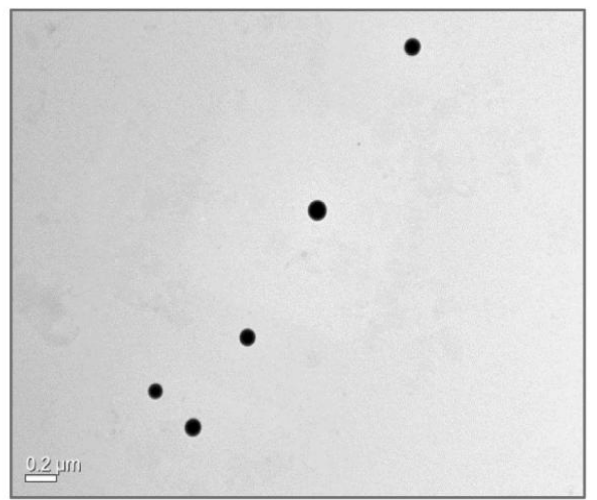

c

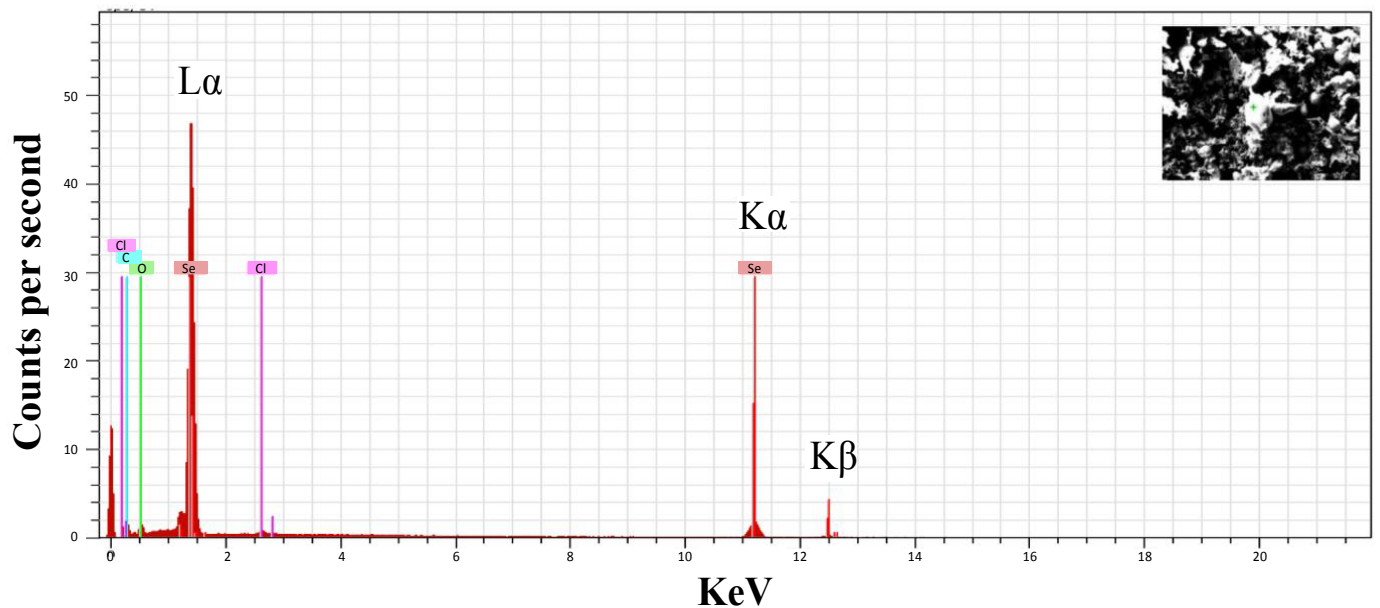

Figure 3: (a) and (b) SEM and TEM images of purified SeNPs showing the shape, size, and non-aggregating nature of the particles. (c) EDX spectra of SeNPs showing the signature peaks of selenium, La, Ka, and Kß (in red). There are no other elements present except $\mathrm{Cl}$ (pink), $\mathrm{C}$ (blue), $\mathrm{O}$ (green), and $\mathrm{N}$ (yellow), which are assumed to be from the X-ray beam channel or elements associated to NPs.

the caspase-3/7 activity. In support to the FACS result, decreased luminescence signals was observed in PC 3 cells treated with $2 \mu \mathrm{g} \mathrm{Se} / \mathrm{mL}$ SeNP for $12 \mathrm{~h}$, suggests low caspase activity in these cells in comparison to untreated cells. While no change in the luminescence was observed in hPBMC. Results implicate that SeNPs are able to induce cytotoxicity in cancerous cells through caspase independent necrotic pathway with no cytotoxicity to non-cancerous hPBMC.

\section{Discussion}

Commercial physical and chemical processes for NP synthesis are not ecofriendly and thus create a burden on our environment. Therefore, there is a growing need to replace these processes with a green synthesis method. In this study, we used the bacterial strain Bacillus licheniformis JS2 for the biological synthesis of SeNPs. In this bacterium the SeNPs are synthesized intracellularly. We developed an improved method for the recovery of intracellular NPs and compared the toxicity of these biogenic SeNPs on human prostrate adenocarcinoma cell line PC3 and hPBMC. Biologically synthesized SeNPs were toxic to PC3 cells by inducing necrosis; however, they appeared to be without significant toxicity to hPBMC.

Extraction of intracellular NPs is challenging because of the difficulty in separating the particles from the cell components. Consequently, no efficient method for this extraction has been reported yet. Shakibaie et al. [21] have reported a method for intracellular NP recovery that uses liquid nitrogen and sonication for bacterial cell lysis. However, we found this method was not effective in lysing all bacterial cells and resulted in association of microbes, both dead and alive, with the extracted NPs. In addition, the extracted particles formed agglomerates.

We performed cell lysis using lysozyme and a French press at 1500 psi. This method is highly effective for obtaining complete lysis. After removal of all soluble cytosolic fractions by Tris- $\mathrm{HCl}$ washes, a twophase extraction system of water-octanol was used for NP recovery. Water-octanol has already been reported as a good partitioning system for the removal of cell wall debris, denatured proteins, and most polysaccharides found in living systems [23]. This procedure resulted in very pure SeNPs with no associated bacteria and only a minute quantity of protein, as confirmed by SEM, EDX, TEM, SDS-PAGE, and FTIR analyses. This appears to be the most successful method for the recovery of intracellular NPs reported thus far.

DLS, SEM, and TEM analyses indicate these NPs do not form agglomerates. We observed an interesting result from Zeta potential analysis that showed a neutral charge on the NP surface. Even while 


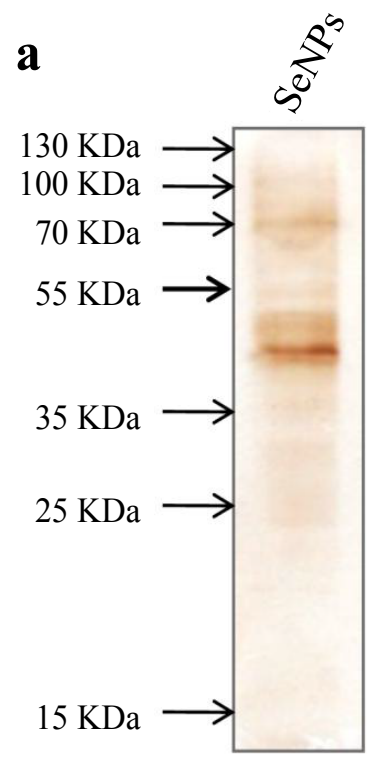

b

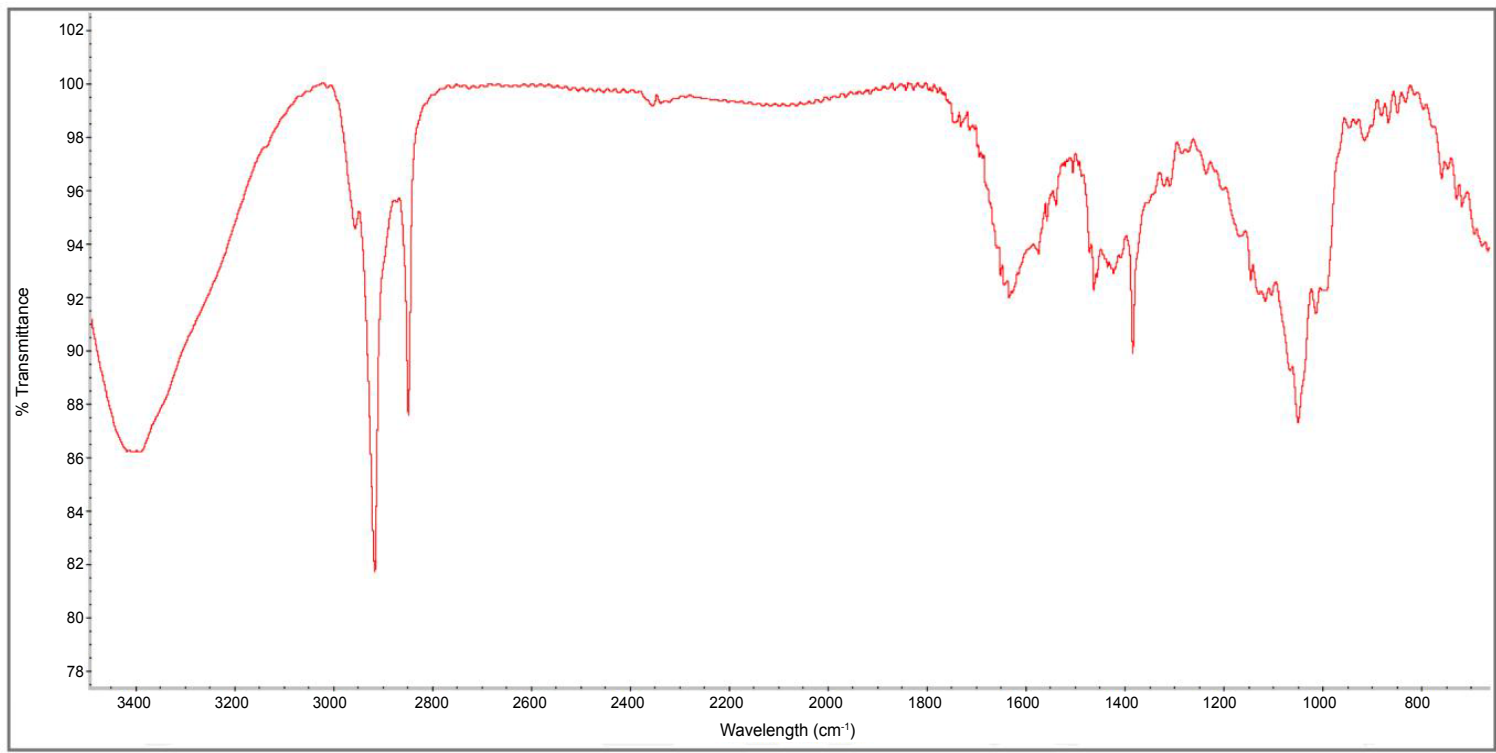

Figure 4: (a) Silver-stained SDS-PAGE (15\%) of SeNPs $(50 \mu \mathrm{g})$ indicating the presence of few proteins. (b) FTIR analysis of SeNPs showing peaks at 3405 , corresponding to the N-H stretch; 2917 and 2849, the C-H stretch; 1634, 1462, and 1384, the amide bond; and 1049, the C-O stretch.

carrying the neutral charge, these particles were stable, not forming agglomerates at physiological temperature, $\mathrm{pH}$ and buffer condition for $5 \mathrm{~h}$, compared to negatively charged particles. As these NPs were more stable at physiological conditions, we hypothesized that the SeNPs may be sterically stabilized. In support to our hypothesis, SDS- PAGE and silver staining results showed that the particles were associated with some protein, although the quantity of protein was very low (Figure 4a). In addition, FTIR analysis showed that the SeNPs have some functional groups attached to the surface (Figure $4 \mathrm{~b}$ ). These findings indicate that our NPs have a polymer and/or protein coating on their surface which provides steric stability to them, as reported previously [24].

Selenium has been shown to be an anticancer agent especially for prostate, colon, and lung cancers. However, the anticancer effect is seen at high doses that adversely affect cell homeostasis and cause severe toxicity $[2,3]$. As the difference between the effective and toxic concentrations of selenium is very marginal, it is vital to maintain the correct amount of selenium to treat the cancer but not cause toxicity. Reports on nano-sized selenium suggest it has similar anticancer activity with excellent bioavailability and lower toxicity compared to other organic and inorganic selenium compounds $[3,4,7,25]$. In this study we show that a concentration of $2 \mu \mathrm{g} \mathrm{Se} / \mathrm{mL}$ of biogenic SeNPs is very effective in inducing necrosis in PC3 cells via caspase-3/7 independent necrotic pathway. This is significantly different from other reports that suggest that SeNPs are able to induce cytotoxicity to 
a
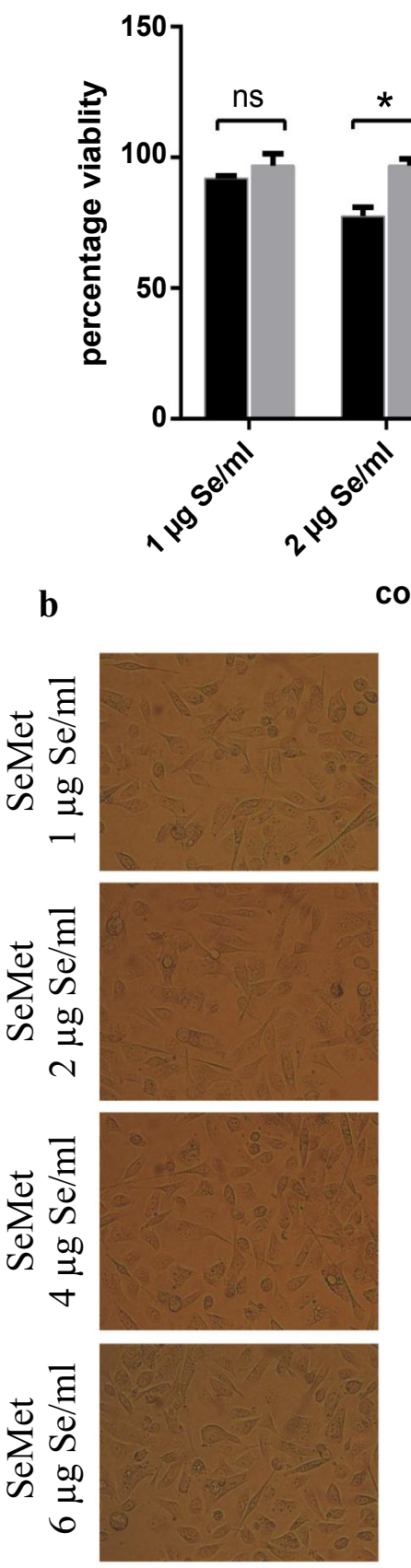

SeNP

SeMet

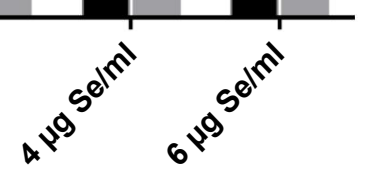

conc of Se
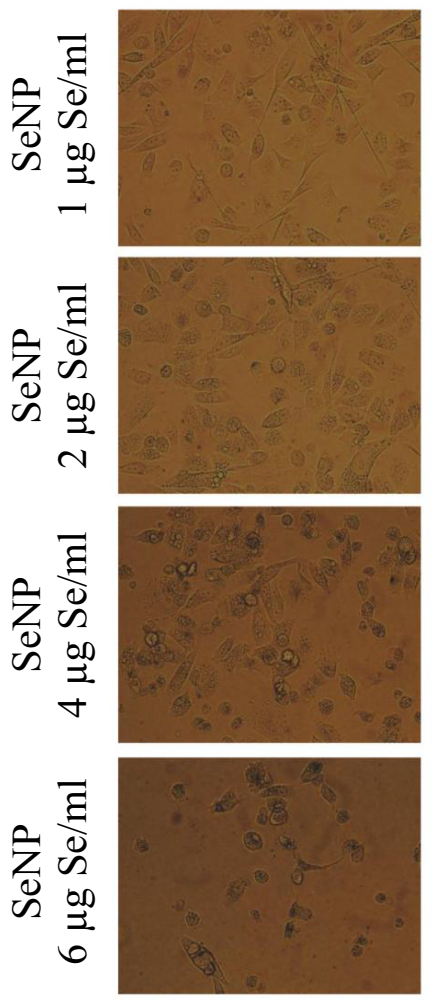

Figure 5: (a) Biogenic SeNPs decrease the viability of PC3 cancer cells. PC3 cells were cultured in the presence of SeNPs or SeMet at 0-6 $\mu \mathrm{g}$ Se/mL concentration for $24 \mathrm{~h}$. Cell viability was quantified by XTT assay. Results were verified by three repetitions of experiments and each experiment was conducted in triplicate. ${ }^{*} p<$ 0.01 represents significant difference in the viability of PC3 cells treated with SeNP or SeMet. The difference in the cell viability between SeNP concentrations of 2 $\mu \mathrm{g} \mathrm{Se} / \mathrm{mL}, 3 \mu \mathrm{g} \mathrm{Se} / \mathrm{mL}$, and $4 \mu \mathrm{g} \mathrm{Se} / \mathrm{mL}$ with respect to $1 \mu \mathrm{g} \mathrm{Se} / \mathrm{mL}$ were also statically significant with $\mathrm{p}$ value $<0$. 01 . (b) Bright field microscopy at a magnification of $40 \mathrm{X}$ representing the morphological responses in PC3 cancer cells after $24 \mathrm{~h}$ of treatment with SeNP or SeMet at 0-6 $\mu \mathrm{g} \mathrm{Se} / \mathrm{mL}$ concentration.

the same extent at $100 \mu \mathrm{g} / \mathrm{mL}$ concentration [21]. The SeNPs in those reports had a surface charge and formed aggregates, which may have led to less availability and efficacy resulting in the requirement for a high concentration to induce apoptosis or necrosis in cancerous cells. The biogenic SeNPs in this report are sterically stabilized and do not form aggregates at physiological conditions, which appears to lead to improved effectiveness. These results suggest that sterically stabilized SeNPs could be a potential candidate for cancer chemotherapy and chemoprevention. Further studies on the pathway behind the induction of necrosis are needed to investigate this potential.

\section{Conclusions}

Use of lysozyme and a French press for bacterial cell lysis followed by an organic-aqueous extraction system is a more successful method for recovery of intracellular NPs then previously used techniques. By using this extraction procedure we obtained pure and clean, sterically 

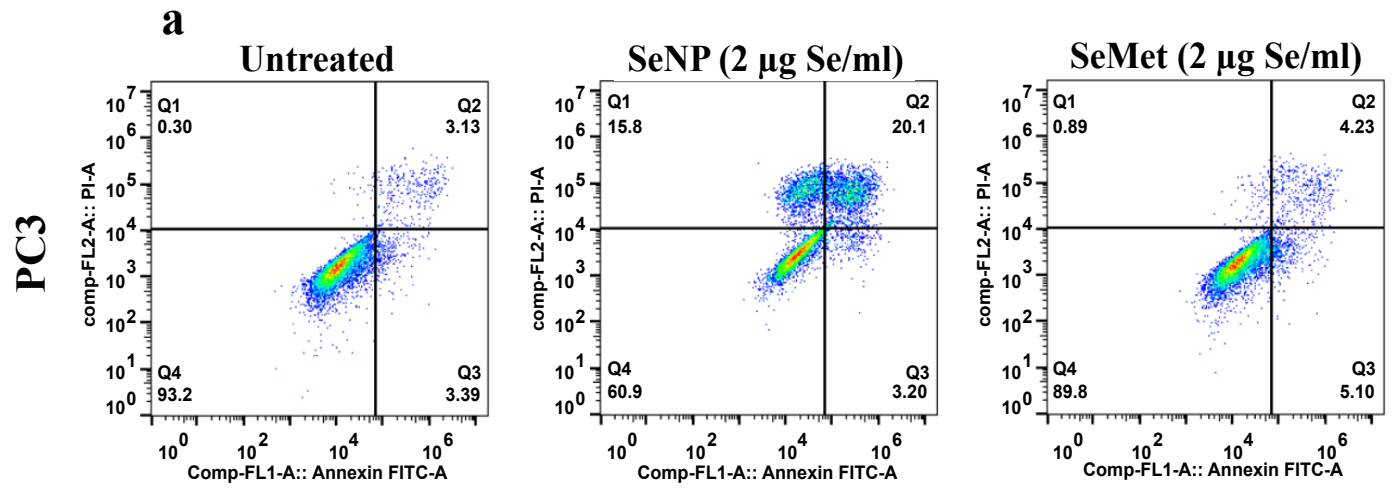

\section{b}
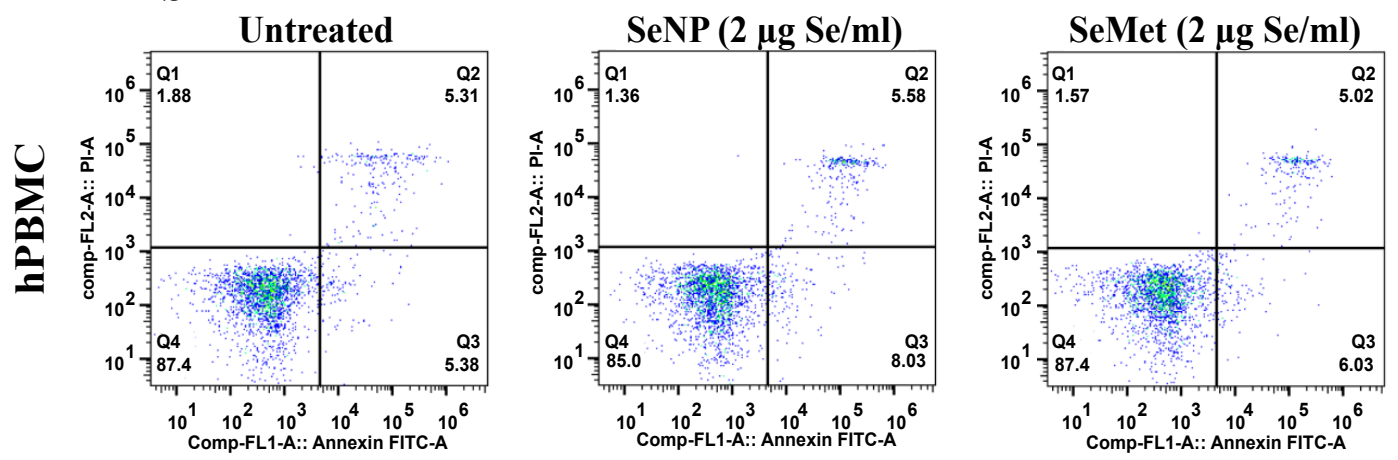

c

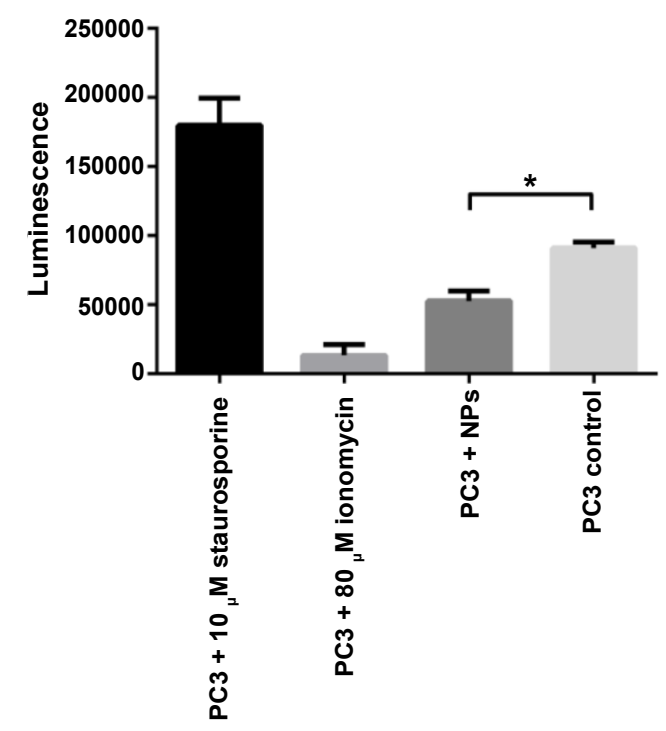

d

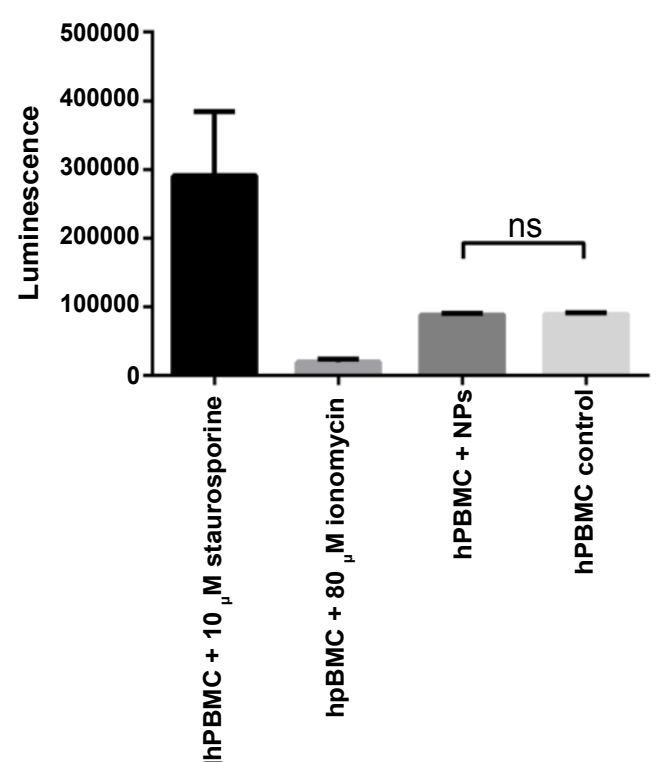

Figure 6: Biogenic SeNPs induced necrosis in PC3 cells but failed to induce apoptosis or necrosis in hPBMC. (a) PC3 cells (b) and hPBMC were cultured in the presence of SeNPs or SeMet at a concentration of $2 \mu \mathrm{g} \mathrm{Se} / \mathrm{mL}$ for $24 \mathrm{~h}$, while the control cells were not treated. The percent of apoptosis/necrosis was measured by Annexin-V and PI staining. Data presented are representative of flowcytometric experiments conducted in triplicate. PC3 cells (c) and hPBMC (d) were cultured in the presence of SeNPs at a concentration of $2 \mu \mathrm{g} \mathrm{Se} / \mathrm{mL}$ for $12 \mathrm{~h}$. Caspase-3/7 activity was measured by using ApoTox-Glo assay kit containing a luminogenic caspase- $3 / 7$ substrate. Cleavage of this substrate by caspases produced a "glow- type" luminescent signal. The amount of luminescence is proportional to the activity of caspases in the cells. Experiment was conducted in triplicate. ${ }^{*} p<0.01$ represents significant difference in the level of caspase-3/7 activity between SeNP treated and untreated PC3 cells 
Citation: Sonkusre P, Nanduri R, Gupta P, Cameotra SS (2014) Improved Extraction of Intracellular Biogenic Selenium Nanoparticles and their Specificity for Cancer Chemoprevention. J Nanomed Nanotechnol 5: 194. doi:10.4172/2157-7439.1000194

Page 9 of 9

stabilized SeNPs from Bacillus licheniformis JS2. Compared to the commercially available selenium supplement SeMet, these NPs are very effective in inducing necrosis via caspase independent necrotic pathway in human prostate adenocarcinoma cells without affecting the viability of hPBMC. To the best of our knowledge this is the first report of uncharged, sterically stabilized biogenic SeNPs that do not form aggregate at physiological conditions and are highly efficacious and specific against prostate cancer at concentration as low as $2 \mu \mathrm{g} \mathrm{Se} / \mathrm{mL}$.

\section{Acknowledgement}

We are grateful to the Director, Institute of Microbial Technology - a constituent laboratory of Council of Scientific and Industrial Research, for providing excellen infrastructure and facility. This study was financially supported by Council of Scientific and Industrial Research (CSIR project head OLP0064); CSIR (fellowship to PS); and the University Grants Commission (fellowship to R.N.).

\section{References}

1. Rayman MP (2000) The importance of selenium to human health. Lancet 356 : 233-241.

2. Fairweather-Tait SJ, Bao Y, Broadley MR, Collings R, Ford D, et al. (2011) Selenium in human health and disease. Antioxid Redox Signal 14: 1337-1383.

3. Wang $\mathrm{H}$, Zhang J, Yu H (2007) Elemental selenium at nano size possesses lower toxicity without compromising the fundamental effect on selenoenzymes: comparison with selenomethionine in mice. Free Radic Biol Med 42: 1524 1533.

4. Zhang JS, Gao XY, Zhang LD, Bao YP (2001) Biological effects of a nano red elemental selenium. Biofactors 15: 27-38.

5. Kong L, Yuan Q, Zhu H, Li Y, Guo Q, et al. (2011) The suppression of prostate LNCaP cancer cells growth by Selenium nanoparticles through Akt/Mdm2/AR controlled apoptosis. Biomaterials 32: 6515-6522.

6. Vekariya KK, Kaur J, Tikoo K (2012) ERÎt signaling imparts chemotherapeutic selectivity to selenium nanoparticles in breast cancer. Nanomedicine 8: 11251132.

7. Zhang J, Wang X, Xu T (2008) Elemental selenium at nano size (Nano-Se) as a potential chemopreventive agent with reduced risk of selenium toxicity: comparison with se-methylselenocysteine in mice. Toxicol Sci 101: 22-31.

8. Lu J, Berndt C, Holmgren A (2009) Metabolism of selenium compounds catalyzed by the mammalian selenoprotein thioredoxin reductase. Biochim Biophys Acta 1790: 1513-1519.

9. Huang Y, He L, Liu W, Fan C, Zheng W, et al. (2013) Selective cellula uptake and induction of apoptosis of cancer-targeted selenium nanoparticles. Biomaterials 34: 7106-7116.
10. Bhattacharya D, Gupta RK (2005) Nanotechnology and potential of microorganisms. Crit Rev Biotechnol 25: 199-204.

11. Oremland RS, Herbel MJ, Blum JS, Langley S, Beveridge TJ, et al. (2004) Structural and spectral features of selenium nanospheres produced by Serespiring bacteria. Appl Environ Microbiol 70: 52-60.

12. Asmathunisha N, Kathiresan K (2013) A review on biosynthesis of nanoparticles by marine organisms. Colloids Surf B Biointerfaces 103: 283-287.

13. Park B, Kang S, Moon W, Roh Y (2013) Microbially induced synthesis of cubic and hexagonal selenium nanoparticles. J Nanosci Nanotechnol 13: 1854-1857.

14. Zhang W, Chen Z, Liu H, Zhang L, Gao P, et al. (2011) Biosynthesis and structural characteristics of selenium nanoparticles by Pseudomonas alcaliphila. Colloids Surf B Biointerfaces 88: 196-201.

15. Debieux CM, Dridge EJ, Mueller CM, Splatt P, Paszkiewicz K, et al. (2011) A bacterial process for selenium nanosphere assembly. Proc Natl Acad Sci U S A 108: $13480-13485$

16. Zhang L, Li D, Gao P (2012) Expulsion of selenium/protein nanoparticles through vesicle-like structures by Saccharomyces cerevisiae under microaerophilic environment. World J Microbiol Biotechnol 28: 3381-3386.

17. Dobias J, Suvorova El, Bernier-Latmani R (2011) Role of proteins in controlling selenium nanoparticle size. Nanotechnology 22: 195605

18. Srivastava SK, Yamada R, Ogino C, Kondo A (2013) Biogenic synthesis and characterization of gold nanoparticles by Escherichia coli $\mathrm{K} 12$ and its heterogeneous catalysis in degradation of 4-nitrophenol. Nanoscale Res Lett 8: 70 .

19. Correa-Llantén DN, Muñoz-lbacache SA, Castro ME, Muñoz PA, Blamey JM (2013) Gold nanoparticles synthesized by Geobacillus sp. strain ID17 thermophilic bacterium isolated from deception Island, Antarctica. Microb Cell Fact 12: 75 .

20. Dhanjal S, Cameotra SS (2010) Aerobic biogenesis of selenium nanospheres by Bacillus cereus isolated from coalmine soil. Microb Cell Fact 9: 52.

21. Shakibaie M, Khorramizadeh MR, Faramarzi MA, Sabzevari $O$, Shahverdi AR (2010) Biosynthesis and recovery of selenium nanoparticles and the effects on matrix metalloproteinase-2 expression. Biotechnol Appl Biochem 56: 7-15.

22. Dhanjal S, Cameotra SS (2011) Selenite stress elicits physiological adaptations in Bacillus sp. (strain JS-2). J Microbiol Biotechnol 21: 1184-1192.

23. Murray MG, Thompson WF (1980) Rapid isolation of high molecular weigh plant DNA. Nucleic Acids Res 8: 4321-4325.

24. Bihari P, Vippola M, Schultes S, Praetner M, Khandoga AG, et al. (2008) Optimized dispersion of nanoparticles for biological in vitro and in vivo studies. Part Fibre Toxicol 5: 14

25. Zhang J, Wang H, Yan X, Zhang L (2005) Comparison of short-term toxicity between Nano-Se and selenite in mice. Life Sci 76: 1099-1109. 